\title{
Thermomechanical response of Mg AZ31 at different levels of temperatures and strain rates
}

\author{
Farid Abed ${ }^{1 *}$, Wael Abuzaid ${ }^{2}$, and Yomna Morad ${ }^{1}$ \\ ${ }^{1}$ Department of Civil Engineering, American University of Sharjah, Sharjah 26666, UAE \\ ${ }^{2}$ Department of Mechanical Engineering, American University of Sharjah, Sharjah 26666, UAE
}

\begin{abstract}
Magnesium alloys' mechanical behavior has received increasing attention because of its high strength to weight ratio making them ideal for various industrial applications, such as vehicle components, transportation and aerospace. The objective of this work is to closely investigate the thermo-mechanical properties of magnesium alloy AZ31 at different strain rates and temperatures. Tensile tests are conducted on a 30 $\mathrm{mm}$ gauge length $\mathrm{MgAZ} 31$ specimens at two quasi-static strain rates $\left(1.11 \times 10^{-3} \mathrm{~s}^{-1}\right.$ and $\left.0.28 \mathrm{~s}^{-1}\right)$ at a range of temperatures between $25{ }^{\circ} \mathrm{C}$ and $250^{\circ} \mathrm{C}$. Digital Image Correlation (DIC) system was used to calculate the true strain and provide quantitative assessment of the localized deformation response at high levels of deformation. The stress-strain responses of MgAZ31 show that the yield stress as well as the ultimate stress decreases as temperature increases and strain rate decreases. Moreover, the difference between the yield and ultimate stresses at both strain rates increases rapidly as temperature increases. The material shows a significant increase in ductility as temperature increases while the modulus of elasticity remains independent of change in strain rates.
\end{abstract}

\section{Introduction}

Magnesium alloys have captured significant interest due to their lightweight and relatively high specific strength. The resulting reduction in structural weight through the use of such light weight alloys is advantageous for many industries, particularly automotive and aerospace [1, 2]. In addition, $\mathrm{Mg}$ alloys have been shown to exhibit excellent biocompatibility and strength characteristics that are ideal for developing biodegradable implants [3]. A wider adoption of $\mathrm{Mg}$ alloys is, however, hindered by the relatively poor ductility at room temperature. Such poor formability can be significantly improved with slight temperature increase of $50-100{ }^{\circ} \mathrm{C}$. However, an accurate description of the temperature and strain rate dependent constitutive response is challenging given the extreme temperature, and strain rate, sensitivity of $\mathrm{Mg}$ alloys.

Various studies have been dedicated to evaluate the temperature dependent mechanical properties of different $\mathrm{Mg}$ alloys. In general, a significant increase in ductility accompanied with strength reduction was observed up to $250{ }^{\circ} \mathrm{C}$ [4]. Beyond 250 and up to $400{ }^{\circ} \mathrm{C}$ an insignificant reduction in strength and limited hardening response were reported which

* Corresponding author: fabed@aus.edu 
indicate a superplastic behavior. Similar observations were also made under biaxial loading conditions [4]. Deformation strain rate has also been shown to have a significant influence on strength and ductility levels $[5,6]$. At the microstructural level, the mechanisms responsible for inducing such changes in mechanical properties are complex. Typically, the enhancement in ductility has been associated with the activation of additional slip systems, including non-basil slip, grain boundary sliding and dynamic recovery mechanisms at elevated temperatures. At high strain rates, the activation of mechanical twinning results in higher strength levels and hardening rates. Such complexities and changes in the underlying deformation mechanisms are not only reflected on the mechanical response of $\mathrm{Mg}$ alloys (i.e., strength and ductility levels), but also influence the intrinsic failure mechanisms responsible for the initiation and progression of damage. It is, therefore, vital to develop constitutive models capable of describing the flow stress of this material by relating the material model constants to the physical quantities at the microstructure level similar to the recent model developed for other types of metals [7-10]. Several papers have studied the mechanical properties of magnesium AZ31 under different loading conditions [11-19].

The objective of this paper is to closely investigate the thermomechanical properties of magnesium AZ31 alloy at different strain rates and temperatures. Tensile experiments are conducted on a $30 \mathrm{~mm}$ gauge length MgAZ31 specimen at two strain rates $\left(1.11 \times 10^{-3} \mathrm{~s}^{-1}\right.$ and $0.28 \mathrm{~s}^{-1}$ ) at a range of temperatures between $25{ }^{\circ} \mathrm{C}$ and $250{ }^{\circ} \mathrm{C}$. Digital Image Correlation (DIC) was used to calculate the true strain and average strain values. Moreover, a constitutive model was developed in order to predict the stress at different strains, strain rates and temperatures. In this conference paper, however, the focus will be on presenting and discussing the stress strain results only, while more details will be presented in a forthcoming extended article.

\section{Experimental program}

The experimental program aims to provide a description of the thermo-mechanical behavior for magnesium alloy MgAZ31 at different loading conditions. The study includes tensile experiments of more than 20 specimens under room- and high- temperatures and at quasistatic loading rates. It also includes scanning electron microscope analysis of tested samples to characterize the fracture surfaces for the considered levels of temperatures and loading rates.

\subsection{Quasi-static tensile test}

In this research, AZ31 magnesium alloy was selected and studied because of its various industrial applications, such as vehicle components, computers, mobile phones and aerospace. The material was available in plates with $3 \mathrm{~mm}$ thickness. Dog-bone shaped tensile specimens with gauge length of $30 \mathrm{~mm}$ and gauge width of $6 \mathrm{~mm}$ (see Fig. 1) were utilized for the quasi static tests which were conducted at room and high temperature.

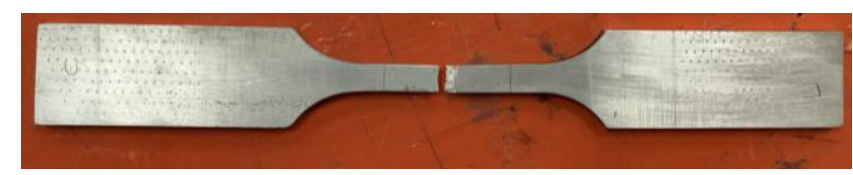

Fig. 1. Sample of Dog-bone AZ31 specimen after failure. 
Uniaxial tensile tests were conducted using a 100-kN Universal Testing Machine (UTM) accompined with heat chamber and Digital Image Correlation (DIC) camera, as shown in Fig. 2. The test matrix included two strain rates of $0.0011 \mathrm{~s}^{-1}$ and $0.28 \mathrm{~s}^{-1}$ and four various temperatures of Room, $50{ }^{\circ} \mathrm{C}, 150{ }^{\circ} \mathrm{C}$ and $250{ }^{\circ} \mathrm{C}$ for each strain rate. At fracture, the specimen was cut to produce an image of the fracture surface, using Scanning Electronic Microscope (SEM). Two samples were tested for each set of conditions.

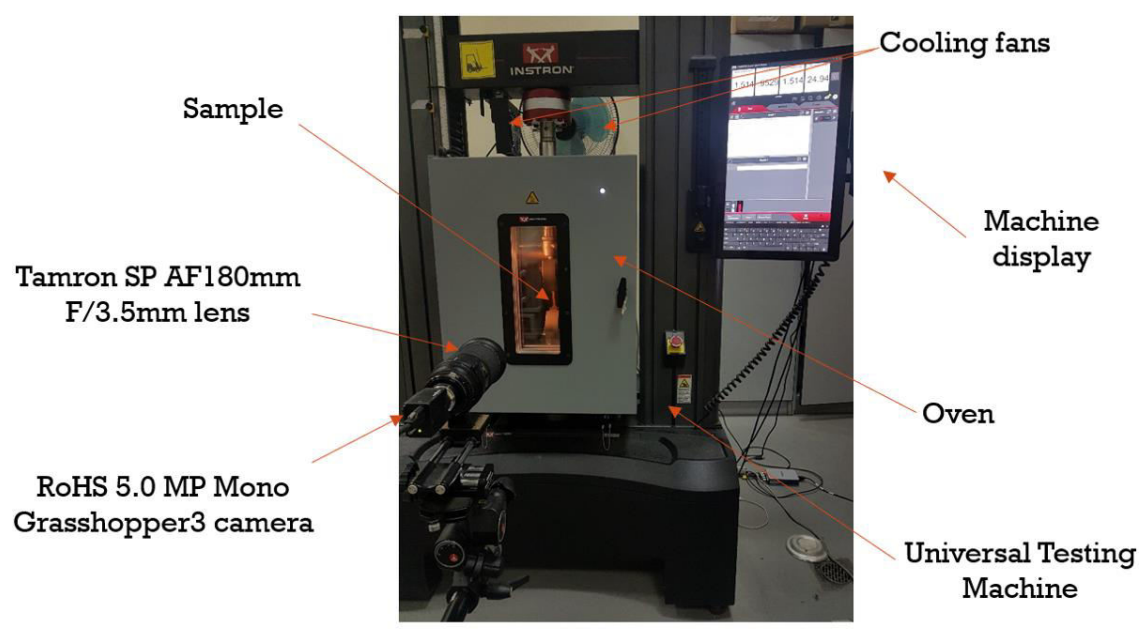

Image correlations done on Vic-2D software

Fig. 2. Test setup used in this study.

The non-contact and full-field technique is ideal for strain measurements using Digital Image Correlation (DIC) at various length scales, deformation temperatures, and strain rates [20-21]. During each experiment, surface images were taken to accurately measure strain by $2 \mathrm{D}$ (DIC) which required a setup of one camera. The image capture rate was varied from one specimen to another depending on the load rate, 1 image per second was used for (2 $\mathrm{mm}$ per $\mathrm{min}$ ) load rate and 75 image per second for (500 $\mathrm{mm}$ per $\mathrm{min}$ ) load rate. The captured images were compared to the zero-load reference image and the correlation of data was performed using Vic2D software. Vic 2D was used for data analysis and was setup at 35 subset size and 5 step size, the area of interest had been selected to cover almost the gauge length (Fig.3).
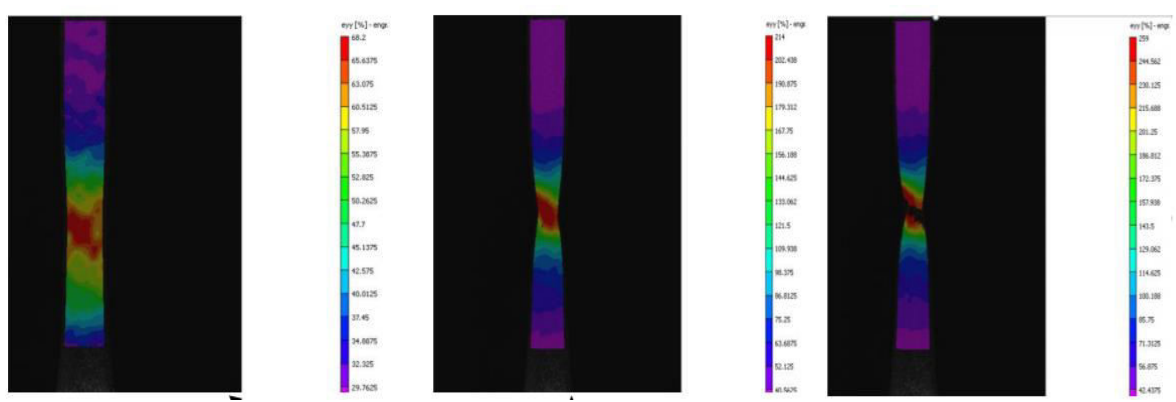

Fig. 3. Sample of strain measurments throughout the test usig DIC. 


\subsection{Scanning Electron Microscope (SEM)}

The Scanning Electron Microscopy (SEM, XL30, Eindhoven, The Netherlands) was used to analyze the fracture surface post failure. SEM sample preparation was followed in order to have a clear fractured surface without changing the mechanical property of the samples. Fig. 4 shows a sample of SEM image for the microstructure of a specimen at fracture tested at room temperature and low strain rate. More details about the SEM results will be presented in an extended paper.

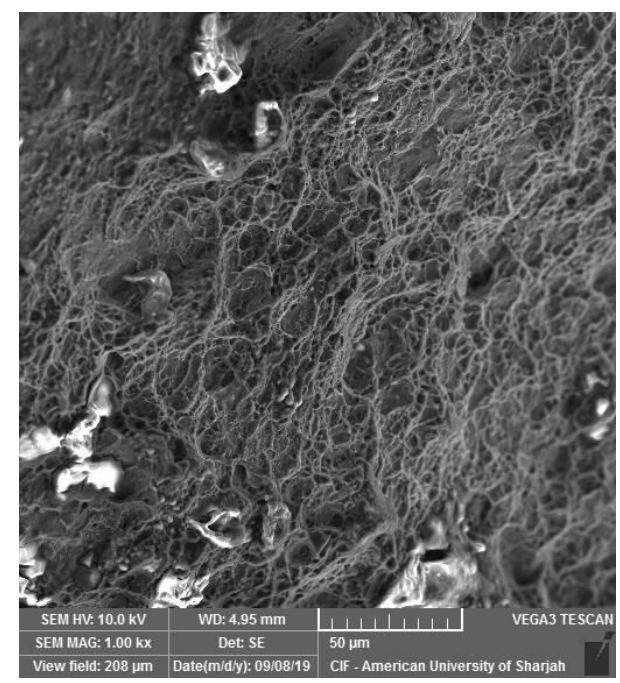

Fig. 4. SEM image for $0.0011 \mathrm{~s}^{-1}$ strain rate at RT

\section{Results and discussions}

\subsection{Quasi-static tensile test}

The thermo-mechanical response of AZ31 magnisum alloy is investigated by conducting a number of quasi-static tensile tests at room and elevated temperatures. The mechanical properties and material contstants evaluated from these experimental results are necessary for constitutive modeling and numerical simulations. Figs. 5 and 6 show the true stress vs true strain curves at low- $\left(0.0011 \mathrm{~s}^{-1}\right)$ and intermediate- $\left(0.28 \mathrm{~s}^{-1}\right)$ strain rates, respectively, and for four different temperatures of $25{ }^{\circ} \mathrm{C}, 50{ }^{\circ} \mathrm{C}, 150{ }^{\circ} \mathrm{C}$, and $250{ }^{\circ} \mathrm{C}$. The results presented in these figures illustrate the coupled temperture and strain rate effect on the stress strain response of the material and its ductility. The material strength clearly decreases with temperature, while the ductility of the alloy increases with temperature increase. Moreover, AZ31 alloy shows less sensitivity to quasi static strain rates at room temperature, however, this effect becomes noticeable at higher temperatures. It is also noticed that the strain hardening of the material diminishes at higher temperatures. On the other hand, more strain hardening was observed at the higher strain rate up to $250{ }^{\circ} \mathrm{C}$ as illustrated in Fig. 6. 


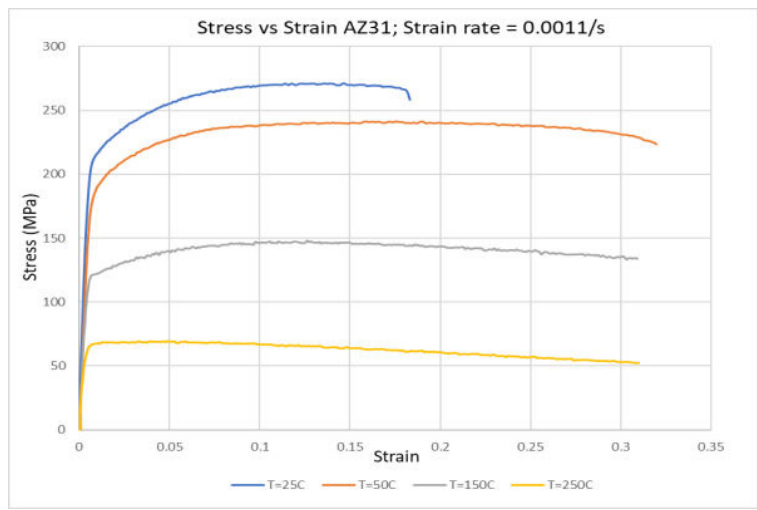

Fig. 5. True stress vs true strain for AZ31 alloy at $0.0011 \mathrm{~s}^{-1}$ and different temperatures.

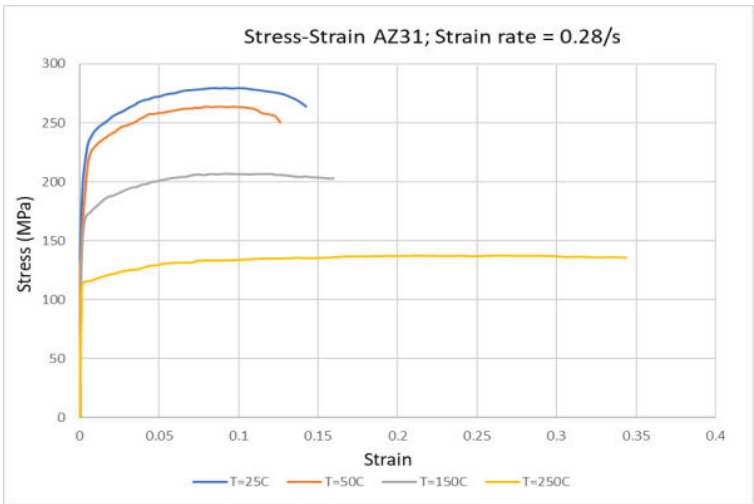

Fig. 6. True stress vs true strain for AZ31 alloy at $0.28 \mathrm{~s}^{-1}$ and different temperatures.

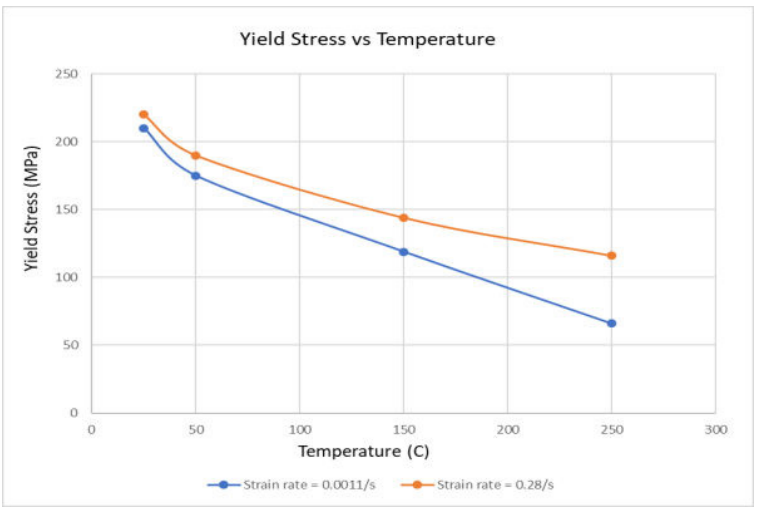

Fig. 7. Variation of initial yielding with temperture for Mg AZ31 alloy.

It can obviously be concluded that the material yield stress is clearly dependent on temperatures, as illustrated in Fig. 7, by the noticeable decrease in the initial yielding at increasing temperatures. The effect of the quasi-static strain rate on the initial yielding was less as compared to the same effect at eleveated tempertures as shown in Fig. 7. Such behavior explains the coupling effect of temperatures and strain rates on the material 
yielding which is dominated at the microstructures by overcoming the Peierls-Nabarro barriers through the movement of the initial dislocations. These observations should be considered when developing a constitutive relation for any alloy to ensure accurate nonlinear finite element simulations of structural applications at elevated temperatures and strain rates [22-24].

\section{Concluding remarks}

The thermo-mechanical behavior of AZ31 alloy is of increasing interest due to its high strength to weight ratio and its wide applications. Finite element simulations of structural applications involving elevated temperatures and strain rates deformation requires the derivation of a robust constitutive relation that is capable of capturing the complex behavior of the material accurately. Any constitutive modeling of crystalline materials, like AZ31, should consider the experimental observation during the plastic deformation and the physical basis of the microstructure inside the material. The experimental results presented in this paper indicated that the flow stress of AZ31 magnisum alloy is dependent on the coupling effect of temperatures and strain rates particularly at elevated temperatures. A complete understanding of this material invlovong constitutive description and finite elment simulations will be dicussed and presented in an extended paper.

\section{References}

1. T. Naka, T. Uemori, R. Hino, M. Kohzu, K. Higashi, F. Yoshida, J. Mater. Process. Technol. Effects of strain rate, temperature and sheet thickness on yield locus of az31 magnesium alloy sheet. 201, 395-400 (2008). doi:10.1016/j.jmatprotec.2007.11.189

2. M. Sanjari, S. Farzadfar, I. Jung, E. Essadiqi, S. Yue, Mater. Sci. Tech-lond. Influence of strain rate on hot deformation behaviour and texture evolution of az31b. 28, 437437 (2012).

3. W. Ali, A. Mehboob, M. Han, S. Chang, Compos. Struct. Experimental study on degradation of mechanical properties of biodegradable magnesium alloy (az31) wires/poly(lactic acid) composite for bone fracture healing applications. 210, 914-921 (2019). doi:10.1016/j.compstruct.2018.12.011M.

4. A. Jäger, P. Lukáč, V. Gärtnerová, J. Bohlen, K. Kainer, J. Alloy. Compd. Tensile properties of hot rolled az31 $\mathrm{mg}$ alloy sheets at elevated temperatures. 378, 184-187 (2004). doi:10.1016/j.jallcom.2003.11.173

5. F. Berge, L. Kruger, H. Ouaziz, C. Ullrich, T. Nonferr. Metal. Soc. Influence of temperature and strain rate on flow stress behavior of twin-roll cast, rolled and heattreated az31 magnesium alloys. 25, 1-13. (2015). doi:10.1016/S1003-6326(15)63572-5

6. A. Rodriguez, G. Ayoub, B. Mansoor, A. Benzerga, Acta Mater. Effect of strain rate and temperature on fracture of magnesium alloy AZ31b. 112, 194-208 (2016). doi:10.1016/j.actamat.2016.03.061

7. F.H. Abed, Mech. Time-Depend. Mat. Constitutive modeling of the mechanical behavior of high strength ferritic steels for static and dynamic applications. 14, 329345 (2010)

8. F.H. Abed, F.S. Makarem, J. Eng. Mater-T. ASME. Comparisons of constitutive models for steel over a wide range of temperatures and strain rates. 134, 21001-21010 (2012).

9. F.S. Makarem, F.H. Abed, Int. J. Impact Eng. Nonlinear finite element modeling of dynamic localizations in high strength steel columns under impact. 52, 47-61 (2012). 
10. F.H. Abed, S.I. Ranganathan, M.A. Serry, Mech. Mater. Constitutive modeling of nitrogen-alloyed austenitic stainless steel at low and high strain rates and temperatures. 77, 142-157 (2014).

11. H. Takuda, T. Morishita, T. Kinoshita, N. Shirakawa, J. Mater. Process. Technol. Modelling of formula for flow stress of a magnesium alloy AZ31 sheet at elevated temperatures. 164-165, 1258-1262 (2005) doi:10.1016/j.jmatprotec.2005.02.034

12. C. Bruni, A. Forcellese, F. Gabrielli, M. Simoncini, J. Mater. Process. Technol. Effect of temperature, strain rate and fibre orientation on the plastic flow behaviour and formability of AZ31 magnesium alloy. 210, 1354-1363 (2010) doi:10.1016/j.jmatprotec.2010.03.025

13. T. Uemori, T. Katahira, T. Naka, N. Tada, F. Yoshida, Procedia Manuf. Cyclic stress and strain responses of AZ31 magnesium alloy sheet metal at elevated temperatures. 15, 1792-1799 (2018) doi.org/10.1016/j.promfg.2018.07.242

14. X. Liu, B. Zhu, C. Xie, J. Zhang, C. Tang, Y. Chen, Mat. Sci. Eng. A. Twinning, dynamic recrystallization, and crack in AZ 31 magnesium alloy during high strain rate plane strain compression across a wide temperature. 733, 98-107 (2018) doi:10.1016/j.msea.2018.07.030

15. F. Kabirian, A. Khan, T. Gnäupel-Herlod, J. Alloy. Compd. Plastic deformation behavior of a thermo-mechanically processed AZ31 magnesium alloy under a wide range of temperature and strain rate. 673, 327-335 (2016) doi:10.1016/j.jallcom.2016.02.145

16. I. Maksoud, H. Ahmed, J. Rödel, Mat. Sci. Eng. A. Investigation of the effect of strain rate and temperature on the deformability and microstructure evolution of AZ31 magnesium alloy. 504, 40-48 (2009) doi:10.1016/j.msea.2008.10.033

17. I. Ulacia, N. Dudamell, F. Gálvez, S. Yi, M. Pérez-Prado, I. Hurtado, Acta Mater. Mechanical behavior and microstructural evolution of a $\mathrm{Mg}$ AZ31 sheet at dynamic strain rates. 58, 2988-2998 (2010) doi:10.1016/j.actamat.2010.01.029

18. C. Tan, S. Xu, L. Wang, Z. Chen, F. Wang, H. Cai, T. Nonferr. Metal. Soc. Effect of temperature on mechanical behavior of AZ31 magnesium alloy. 17, 41-45 (2007). doi:10.1016/S1003-6326(07)60045-4

19. G. Bajargan, G. Singh, D. Sivakumar, U. Ramamurty, Mat. Sci. Eng. A. Effect of temperature and strain rate on the deformation behavior and microstructure of a homogenized AZ31 magnesium alloy. 579, 26-34 (2013). doi:10.1016/j.msea.2013.04.088

20. W. Abuzaid, H. Sehitoglu, J. Lambros, Mater. Sci. Eng. Plastic strain localization and fatigue micro-crack formation in Hastelloy X. 561, 507-51 (2013). https://doi.org/10.1016/j.msea.2012.10.072

21. W. Abuzaid, H. Sehitoglu, J. Lambros, Mater. High Temp. Localisation of plastic strain at the microstructurlal level in Hastelloy X subjected to monotonic, fatigue, and creep loading: the role of grain boundaries and slip transmission. 33, 384-400 (2016) https://doi.org/10.1080/09603409.2016.1152421

22. G.Z. Voyiadjis, F.H. Abed, Model. Simul. Mater. Sc. Transient localizations in metals using microstructure-based yield surfaces. 15, S83 (2007).

23. F.H. Abed, G.Z. Voyiadjis, Int. J. Multiscale Com. Adiabatic shear band localizations in BCC metals at high strain rates and various initial temperatures. 5, 325-349 (2007).

24. F.H. Abed, G.Z. Voyiadjis, J. Eng. Mech-ASCE. Thermodynamic consistent formulations of viscoplastic deformations in FCC metals. 133, 76-86 (2007). 